\title{
The Value of Physical Education and Wellness for the First-Year Student
}

\author{
Jennifer L. Buckley
}

In 1996 the United States Surgeon General published a report that specifically addressed physical activity and health. The main purpose of the report was to outline the role that physical activity plays in the prevention of disease. This report emphasized that health benefits are proportional to the amount of physical activity an individual experiences (National Center for Chronic Disease Prevention and Health Promotion, 1996). Along with this summary, some astounding statistics about the amount of physical activity that Americans experience were also revealed. According to the National Center for Chronic Disease Prevention and Health Promotion (1996), "more than 60\% of American adults are not regularly physically active" (p. 3), and "significant health benefits can be obtained by including a moderate amount of physical activity, such as 30 minutes, on most, if not all, days of the week and that through this modest increase in daily activity, most Americans can improve their health and quality of life" (p. 3).

The statistics related to physical fitness and American youth can be viewed as even more astounding. "Nearly half of American youths 12-21 years of age are not vigorously active on a regular basis. Moreover, physical activity declines dramatically during adolescence" (p. 3). Wang and Beydoun (2007) state that "childhood obesity is real, as 10 million children ages $6-19$ were considered overweight."

The message is clear; the majority of Americans are physically inactive and as a result are at a greater risk of developing a disease. Action needs to be taken in an attempt to decrease the amount of physically inactive people in our country. Wang and Beydoun (2007) state, "In 2015, it is predicted that $75 \%$ of adults will be overweight and $41 \%$ obese." Physical education requirements at the elementary and secondary levels are falling behind. As a result of various budget constraints and the No Child Left Behind Act, mandatory physical education programs are often an afterthought. Ownership needs to be taken by institutions of higher learning. All first-year college students should be required as part of their general education curriculum to take two semesters of a physical education course. Support for the implementation of the policy will begin by a general overview of physical education programs in higher education. The definition of freshman success will be addressed with specific references to maintaining personal health and wellness. Lastly, the legal implications for instituting a mandatory physical education/well-

Jennifer L. Buckley (jbuckley@aurora.edu) is an Instructor of Physical Education in the School of Health and Physical Education at Aurora University. 
ness course at private institutions of higher learning will also be outlined.

The benefits of physical activity are clearly established. Regular physical activity reduces the risk of premature mortality, coronary heart disease, hypertension, colon cancer, and diabetes mellitus. Moreover, physical activity also improves mental health (National Center for Chronic Disease Prevention and Health Promotion, 1996). A rising trend is a move towards a holistic approach towards health and physical activity with the concept of wellness. As Jesse Williams (1922) stated in Upcraft and Gardner (1989), "It is of value to think of health as that condition of the individual that makes possible the highest enjoyment of life, the greatest constructive work, and that shows itself in the best service to the world. Health as freedom from disease is a standard of mediocrity, health as a quality of life is a standard of inspiration and increasing achievement" (p. 157). The concept of wellness is not solely limited to physical activity. It encompasses a means by which choices are made towards a healthy lifestyle.

According to Hettler (1980), there are six dimensions of wellness: emotional development, intellectual development, physical development, social development, occupational development, and spiritual development. He further explains, "A person who exhibits wellness in any one of these dimensions experiences an extension of that well-being to other dimensions. A lack of wellness in any one of these dimensions will also affect other dimensions, diminishing the person's well-being in those areas" (Upcraft \& Gardner, 1989, p. 157).

The university curriculum provides an excellent opportunity to incorporate and raise the level of awareness of health and wellness behaviors. Courses designed to raise the level of health-related fitness knowledge may assist in the counter balance associated with the negative lifestyle often associated with the college experience (Adams, Graves, \& Adams, 2006, I 4). Examples of negative lifestyle behaviors may include limited physical activity, high levels of academic stress, poor diet, and increased alcohol use.

The status of required physical education and wellness courses in colleges and universities has changed over the past few decades. In the 1960s, 90\% of colleges and universities maintained some form of a physical education requirement for undergraduate students (Hensley, 2000, p. 31, 32). A more recent study conducted by Hensley (2000) reported that $63 \%$ of institutions required some form of required physical education prior to graduation (p. 32). As far as the number of semester hours required for graduation at these schools, Miller, Dowell, and Pender (1989) reported that of the institutions that require physical education for graduation, a two-hour requirement was the most prevalent at $44 \%$, while a four-hour requirement was reported by $22 \%$ of the schools (p. 21 ).

An example of an institution that requires a two-hour physical education/ wellness course for all undergraduate students is Ball State University. The required course combines physical activity with specific lecture topics related to wellness. Along with the required two-hour physical education/wellness course, Ball State offers wellness-orientated residence halls, an Institute for Wellness, and wellness programming for faculty, staff, and students. Administrators believe that their total 
university commitment to health and wellness allows students at Ball State University to explore all the various dimensions of wellness (Robbins, Powers, \& Rushton, 1992, p. 17).

Another institution that has made a commitment to health and wellness is Oral Roberts University. At Oral Roberts, the founding philosophy "is to provide an education which seeks to develop the whole person with equal emphasis on mind, spirit, and body. Oral Roberts University wants its graduates to be mentally alert, spiritually alive, and physically fit" (Brynteson, 1978, p. 37). Oral Roberts requires more than a two-hour requirement from their undergraduate students; all students are required to pass a physical education activity course each semester. The goal of the required physical education course each semester is to "give students a basic knowledge of exercise physiology and exercise prescription that will help them develop and maintain a lifelong personal fitness program" (Brynteson, 1978, p. 38).

Many institutions such as Ball State and Oral Roberts Universities have required physical education and wellness courses that are mandatory for all undergraduate students. The question is, what impact does the required physical education and wellness course have on students after they graduate from these institutions? Do required physical education and wellness courses have immediate and long-term effects on these students? A study conducted by Adams, Graves, and Adams (2006) specifically looked at the effectiveness of such courses. In their study, they investigated a university level, conceptually-based, health-related fitness course. This specific course was offered as a two-credit hour general education course requirement ( $\$ 12$ ).

Upon completion of the course, students were expected to be able to: identify and describe the relationship between lifestyle and selected health problems, evaluate their current lifestyle in relationship to future health problems, describe the concepts and components of health-related fitness, evaluate their personal health-fitness, develop knowledge and skill necessary to successfully participate in at least one lifetime physical activity, and prescribe a personal health-fitness program including physical activity and weight control. Course requirements also included students' participation in physical activity. Class activities were designed to: (1) teach the proper use of equipment for resistive training, (2) teach appropriate methods and procedures associated with flexibility activities designed to improve specific joint range of motion, and (3) teach the proper method of implementing an aerobic based exercise program. (Adams, Graves, \& Adams, 2006, $\uparrow 12,15$ )

Results of this study indicated that students that complete the required two-credit general education course present significantly greater levels of healthrelated fitness knowledge than those who have never been exposed to the course. Students also retain a significantly higher level of knowledge throughout their college career than those who never completed the course (Adams, Graves, \& Adams, 2006, ๆ 20). 
A study conducted by Welle and Kittleson (1994) looked at the impact of college health education and physical education courses on personal wellness. The subjects in their study attended a university that required that students "complete a 3-credit hour course in health education and three 1-credit hour physical education activity course for graduation" ( 14). Results of their study indicated that "traditional health education courses have an impact on improving student's overall wellness." Furthermore, "physical education courses on the other hand saw no significant improvement in wellness scores" (\$30). In conclusion, combining the health course with the physical education course (i.e., a classroom lecture and laboratory activity sessions) may be the direction that universities want to take instead of separating the health (lecture course) from the physical (activity course).

The ultimate goal of general education is to incorporate courses that will be meaningful and will have an impact on the lives of students. Requiring all undergraduate students to take a physical education/wellness course through the general education curriculum provides the greatest opportunity in higher education for health and physical education to have an impact on the lives of students (Trimble and Hensley, 1990, p. 69). More importantly, it is vital that undergraduate students take a required physical education/wellness course during the first year experience. Doing so will ultimately assist in determining freshman success.

Upcraft and Gardner (1989) believe that freshmen succeed when they make progress toward their goals by: "(1) developing academic and intellectual competence; (2) establishing and maintaining interpersonal relationships; (3) developing identity; (4) deciding on a career and life-style; (5) maintaining personal health and wellness; and (6) developing integrated philosophy of life (p. 2)." Integrating a required physical education and wellness course into the first year enables freshmen to be mindful of the impact college has on their physical and emotional well-being. Upcraft and Gardner (1989) further explain the importance of health and wellness during the freshmen year by encouraging students "to think of maintaining health and wellness as an active rather than reactive process (p. 3)."

Another belief necessary for freshman success is involvement. Astin (1985) stated that "to succeed, freshmen must be committed to involving themselves in the intellectual and extracurricular life of the campus. To help them succeed, institutions must provide enriched opportunities for such involvement" (Upcraft \& Gardner, 1989, p. 4). Requiring first-year students to get involved in physical activity programs that force them to be actively involved provides an excellent opportunity to commit to this belief. The student body president at Oral Roberts University described the aerobics center as "the center of student activity at ORU" and went on to state that "if you are looking for someone or looking for something to do, the Aerobics Center is the place to go" (Brynteson, 1978, p. 39).

The freshman year does not prepare students for optimal living. Many students will experience an increased amount of stress as a result of an inability to manage 
their time, poor diet, physical inactivity, and increased alcohol use. Frederick Leafgren made the following statement in Upcraft and Gardner (1989) in regards to the first-year student:

Living at their optimum levels-physically, intellectually, emotionally, socially, and spiritually_can enhance their chances for success. A wellness-oriented lifestyle results not only in a strong personal commitment to one's well-being but also in a strong commitment to continued involvement in the institution. If we can convince freshmen that changing their patterns of behavior will not only enable them to reach their academic potential but also have a powerful effect on their well-being for the remainder of their lives, we have an excellent chance at making significant changes in the living patterns of a larger population in future years. (p. 157)

The freshman year is the best time to introduce the idea of developing a wellness lifestyle. Requiring all first year college students to take a physical education and wellness course as part of their general education requirement will prepare students for optimal living.

It is evident that there is support for the implementation of a physical education/wellness course during the freshmen year. It is important to examine the legal implications of instituting such a policy at institutions of higher learning. A physical education/wellness course that has a lecture and a laboratory component provides some questions to those first-year students that have disabilities or pre-existing medical conditions. Kaplan and Lee (2007) give an overview of evaluating students with disabilities by explaining the Rehabilitation Act and the Americans With Disabilities Act of 1990. They state the following:

The Rehabilitation Act and the Americans With Disabilities Act of 1990 require colleges and universities to provide reasonable accommodations for students with disabilities. Although the laws do not require institutions to change their academic criteria for disabled students, institutions may need to change the format of tests; to provide additional time, or readers or aides, to help students take examinations; or to change minor aspects of course requirements.

(p. 446)

Requiring all first-year students to take a physical education/wellness course that has an activity requirement may pose some questions as to whether or not certain individuals will be able to complete such a mandate. Kaplan and Lee (2007) state, "The ADA defines disability as a physical or mental impairment that substantially limits one or more of the major life activities of the individual" (p. 447). Individuals should be evaluated on a case by case basis to determine whether or not they will be able to participate.

Oral Roberts University addresses this issue by having each student complete a series of medical tests administered by the Human Performance Laboratory and Student Health Services. Tests such as medical history, blood analysis, 
electrocardiogram (EKG), and heart and lung exams are administered to each student. These tests call attention to special needs any student may have (Brynteson, 1978, p. 38).

Although this works for Oral Roberts University, many colleges and universities do not have a Human Performance Laboratory or have Student Health Services that are able to complete such exams. If campus services are unavailable to complete such prescreening, then students must receive a comprehensive physical prior to their arrival on campus during the first year. Special assistance will be given to those students who need an adaptive exercise prescription. Examples of those individuals may include, but are not limited to, those that have a documented physical disability such as a spinal cord injury, a prosthetic limb, or hearing or visual impairment. Having separate sections of courses would appropriately accommodate those individuals with disabilities under the ADA.

Most colleges and universities that currently have a required physical education and wellness course for undergraduate students are following this protocol for those individuals that have a disability or a pre-existing condition. A study conducted by Trimble and Hensley (1990) classified these schools as offering special opportunities courses. They went on to reveal, "Approximately one-third of all institutions reported the availability of at least one section of adapted physical education in the curriculum." They also stated, "Of those institutions offering an adapted program, 73\% utilized medical evaluation procedures" (p. 71).

Requiring all students to have an extensive medical examination from a physician protects the university from any legality involved in determining who can or cannot participate in physical activity. Additionally, by receiving such information as height, weight, EKG, and blood profiles, students have a baseline by which to compare in their future years.

Of the $63 \%$ of institutions that require some form of a physical education/ wellness course prior to graduation as reported by Hensley (2000), there was no distinction as to whether the institutions were private or public. There was a distinction, however, in student enrollments. Of those institutions enrolling between 500 and 1,000 students, $83 \%$ have a physical education requirement. Conversely, institutions that have a student enrollment of greater than 20,000, $37 \%$ have a physical education requirement (Hensley, 2000, p. 32). Even though no distinction was made between public and private institutions, inferences can be made that those institutions with smaller student enrollments are more likely to be private institutions than the larger enrollments typically seen with public schools.

It may be easier for smaller, private schools to incorporate the mandatory physical education and wellness during the first year. Some possible reasons may be that it is easier to track medical records of a smaller group of students. Incorporating such a program also requires adequate facilities and staff. If a course is required of all first-year students, more faculty are needed to accommodate the classes. Public institutions also have to put any curricular changes through their governing boards and/or state legislatures which can possibly take 2 to 3 years. This could be another reason why more private institutions incorporate mandatory 
physical education as oppose to public institutions. It is easier for private institutions to change curriculum within their own governance structure than with the external governing boards associated with curricular changes involved with public schools.

The message is clear that there is a need for Americans to be physically active. Since the United States Surgeon General published the report on Physical Activity and Health in 1996, it is documented and supported by research that individuals can prevent disease and improve their health and quality of life by incorporating physical activity into their lives. Incorporating a mandatory physical education and wellness course into the freshman year of college provides an excellent opportunity for colleges to commit to the philosophy that a healthy lifestyle is not only a vital part of the college experience, but also to life after graduation. Health and wellness education is essential to freshman success. It allows institutions of higher learning to be active in wellness education instead of being reactive to some of the negative lifestyle choices that students make during their first year. Incorporating a physical education and wellness course where students receive content through a lecture and active participation through laboratory experience allows the students to make the connection from theory to practical application in their own lives. Educating first-year students of the value of regular physical activity and wellness is essential and will not only benefit the college community, but will also benefit the lives of every student that attends the university for years to come.

\section{References}

Adams II, T. M., Graves, M. M., \& Adams, H. J. (2006). The effectiveness of a university level conceptually-based health-related fitness course on healthrelated fitness knowledge. Physical Educator, 63(2), 104-112. Retrieved March 4, 2008, from Academic Search Complete database.

Brynteson, P. (1978). Fitness for life: Aerobics at Oral Roberts University. Journal of Physical Education and Recreation, 49(1), 37-39.

Hensley, L. D. (2000). Current status of basic instruction programs in physical education at American colleges and universities. Journal of Physical Education, Recreation, \& Dance, 71(9), 30-36.

Kaplin, W. A., \& Lee, B. A. (2007). The law of higher education (4th ed.). San Francisco, CA: Jossey-Bass.

Miller, G. A., Dowell, L. J., \& Pender, R. H. (1989). Physical activity programs in colleges and universities: A status report. Journal of Physical Education, Recreation, \& Dance, 60(6), 20-23.

National Center for Chronic Disease Prevention and Health Promotion, A Report of the Surgeon General. (1996). Physical activity and health. Retrieved March, 15, 2008, from http://www.cdc.gov/nccdphp/sgr/intro.htm

Robbins, G. C., Powers, D., \& Rushton, J. (1992). A required fitness/wellness course that works. Journal of Physical Education, Recreation, \& Dance, 63(2), 17-21. 
Trimble, R. T., \& Hensley, L. D. (1990). Basic instruction programs at four-year colleges and universities. Journal of Physical Education, Recreation, \& Dance, 61(6), 64-73.

Upcraft, M. L., Gardner, J. N., \& Associates. (1989). The freshman year experience: Helping students survive and succeed in college. San Francisco, CA: Jossey-Bass.

Wang Y., \& Beydoun, M. A. (2007). The obesity epidemic in the United Statesgender, age, socioeconomic, racial/ethic, and geographic characteristics: A systemic review and meta-regression analysis. Epidemiologic Reviews, 29(1), $6-28$.

Welle, H. M., \& Kittleson, M. J. (1994). Impact of college health education and physical education courses on personal wellness. Wellness Perspectives, 10(3). Retrieved March 11, 2008, from Academic Search Complete database. 